\title{
HIPEROXIA HIPERBÁRICA EM INFECÇÕES GRAVES E SEPSE - CONCEITOS E PERSPECTIVAS
}

\author{
HYPERBARIC HYPEROXIA IN SEVERE INFECTIONS AND SEPSIS - CONCEPTS AND PERSPECTIVES
}

Paulo E. lazzetti ${ }^{1} \&$ Mário Mantovani²

\begin{abstract}
1Docente do Serviço de Medicina Hiperbárica da Disciplina de Fisiologia e Metabologia Cirúrgica e ${ }^{2}$ Docente da Disciplina de Cirurgia do Trauma do Departamento de Cirurgia. Faculdade de Ciências Médicas - Universidade Estadual de Campinas.

Correspondência: Prof.Dr. Paulo E. lazzetti - Serviço de Medicina Hiperbárica / Hospital das Clínicas / UNICAMP - CEP 13 100-000 Cidade Universitária Zeferino Vaz, Campinas, SP. E-mail: iazzetti@bestway.com.br
\end{abstract}

IAZZETTI PE \& MANTOVANI M. Hiperoxia hiperbárica em infecções graves e sepse - Conceitos e perspectivas. Medicina, Ribeirão Preto, 31: 412-423, jul./set. 1998.

RESUMO: Efetua-se uma revisão da forma como a hiperoxigenação hiperbárica pode interferir em alguns dos fatores do quadro séptico, em especial na sepse provocada por infecções intra-abdominais, envolvendo bactérias Gram-negativas, destacando-se o seu interesse para a pesquisa experimental e clínica. São considerados alguns conceitos de hipoxia e metabolismo oxidativo na sepse, revisando-se o papel dos radicais ativados do oxigênio e antioxidantes, nesta síndrome. Conceituam-se as bases do uso da hiperoxia hiperbárica em infecções graves e sua utilização clinica atual.

UNITERMOS: Oxigenação Hiperbárica. Infecção. Sepse.

\section{INTRODUÇÃO}

A hiperoxigenação hiperbárica (oxigenoterapia hiperbárica ou $\mathrm{OHB})$, embora já descrita em meados do século passado, só começou a ser utilizada em ambiente hospitalar a partir da década de trinta. Desde então, tem sido usada em infecções graves, notadamente anaeróbicas ou mistas, tais como celulites, fasciítes e miosites necrotizantes. A OHB consiste na inalação de $100 \%$ de oxigênio, em uma pressão superior à condição atmosférica, ao nível do mar (760 mmHg), situação obtida quando o indivíduo está no interior de compartimentos selados, resistentes a pressão: as câmaras hiperbáricas. $\mathrm{O}$ potencial terapêutico da OHB ocorre na medida em que altas doses de oxigênio, proporcionadas pela elevação da pressão ambiente, possam compensar determinadas condições de hipoxia e que esta compensação, através de exposições breves e intermitentes, seja eficaz para alterar o curso do desenvolvimento da patologia. Em nosso país, o CREMESP e, posteriormente, o CFM, regulamentaram o uso e indicações desta terapêutica, em 1995 (Ver Apêndice).

Por outro lado, a base fisiológica, na terapêutica de infecções e da sepse, evoluiu substancialmente na última década, principalmente através dos avanços da Biologia Celular, Genética e Imunologia. Apesar do progresso do conhecimento nestes diversos campos, a sepse continua apresentando incidência crescente e suas conseqüências constituem, ainda, um desafio quanto à terapêutica.

A potencial compensação da hipoxia proporcionada pela OHB tem grande interesse de pesquisa, uma vez que se associa, na hipoxia decorrente da sepse, à liberação dos mediadores envolvidos na resposta inflamatória sistêmica. As enzimas antioxidantes são um relevante fator de proteção do organismo, no caso de a resposta inflamatória generalizar-se. Como a 
hiperoxigenação hiperbárica é um estímulo para a ativação e síntese destas enzimas, este aspecto também se reveste de importância peculiar. Um número crescente de pacientes sépticos estará recebendo esta terapêutica nos próximos anos, considerando-se as indicações já estabelecidas e tendo em conta a expansão desta nova modalidade de tratamento.

Como a hiperoxigenação hiperbárica pode interferir em alguns dos múltiplos fatores relacionados ao desenvolvimento e progressão do quadro séptico, em especial na sepse provocada pela flora intestinal, são aspectos de grande interesse de pesquisa experimental e clínica na terapia intensiva e constituem-se em objeto desta revisão.

\section{Hipoxia - Definições}

A condição de normoxia é definida, em termos ideais, como a tensão de oxigênio $\left(\mathrm{PO}_{2}\right)$ no ar inspirado suficiente e adequada para manter o metabolismo aeróbio e a homeostase nos vários tecidos ${ }^{(1)}$. O transporte de oxigênio entre o ar inspirado e a sua utilização pelos tecidos passa por várias etapas, ao longo das quais a $\mathrm{PO}_{2}$ vai se reduzindo até que as moléculas deste gás possam ser efetivamente utilizadas como oxidante final, na cadeia respiratória das cristas mitocondriais. Qualquer comprometimento, em alguma destas fases, que possa diminuir o aporte de oxigênio a determinado tecido, em níveis críticos, resultará em hipoxia e provocará metabolismo anaeróbio, acidose láctica, lesão celular, hipercalemia e falência de tecidos e órgãos.

As infecções graves e a sepse provocam uma reação sistêmica complexa, caracterizada por comprometimento cardiopulmonar e metabólico, que apresentam dois estágios clínicopatológicos distintos: a fase hiperdinâmica (inicial) e a fase hipodinâmica (tardia). Na primeira, observa-se um débito cardíaco normal ou elevado, hipoxemia, diminuição da pressão venosa central, resistência vascular periférica diminuída, hiperventilação, hiperlactatemia e extremidades normotérmicas. A progressão para o estágio hipodinâmico ocorre com diminuição do débito cardíaco, alta resistência periférica, hipotensão, oligúria e extremidades hipotérmicas e/ou cianóticas ${ }^{(2)}$. Como, paralelamente, o catabolismo está aumentado, há considerável hidrólise de ATP e a extração tissular de oxigênio está comprometida na sepse, ocorrendo glicólise anaeróbia ${ }^{(3)}$. Resultando, na conversão final do piruvato, em ácido láctico. Ao contrário, na glicólise aeróbia, o piruvato é convertido a acetil-coenzima A pelo complexo da desidrogenase pirúvica ${ }^{(4)}$. Friedman et al. ${ }^{(5)}$, apontam ser a concentração do lactato sérico um melhor indicador prognóstico, na sepse, do que as variáveis relacionadas ao oxigênio. $\mathrm{O}$ mesmo autor ressalta que a $\mathrm{PCO}_{2}$ nos tecidos também apresenta superior qualificação prognóstica. Na sepse, associam-se disfunções que diminuem a oferta ${ }_{2}$ assim como fatores que comprometem a utilização de oxigênio pelos tecidos ${ }^{(6)}$.

Uma importante disfunção, iniciada ainda na fase hiperdinâmica, é a redução na capacidade dos tecidos em extrair o oxigênio suficiente para seu metabolismo. A administração de endotoxina ou bactérias em modelos experimentais reproduzem esta situação. Dois mecanismos causais, principais são apontados: distúrbios microvasculares e comprometimento direto do metabolismo celular ${ }^{(7)}$.

Quanto ao fator microvascular, sabe-se que os mediadores inflamatórios, liberados provocam uma série de efeitos. Afetam o controle vasomotor, provocam edema endotelial e intersticial e causam microembolismos leucocitários, provocando uma hipoxia por disfunção de perfusão (disperfusão). Experimentos, em que se produz embolização por microesferas, mimetizam esta situação ${ }^{(7)}$.

No caso de decréscimo na capacidade intrínseca dos tecidos de metabolizarem o oxigênio apropriadamente, estariam comprometidos mecanismos intracelulares, envolvidos na utilização deste gás. As disfunções mitocondriais, que resultariam em hipoxia por desacoplamento ou histotóxica, são um dos fatores apontados. Na hipoxia por desacoplamento, por exemplo, ocorre a oxidação de substrato, mas este processo não forma ATP em quantidades proporcionais, normais. Na hipoxia histotóxica, a própria cadeia respiratória seria bloqueada, não ocorrendo oxidação de substrato. A integridade e eficiência do processo de fosforilação oxidativa, na sepse, devem, sem dúvida, ser melhor elucidadas ${ }^{(8)}$.

A deficiente extração de oxigênio, que pode ocorrer na sepse, explica a $\mathrm{PO}_{2}$ normal ou elevada, observada em vários tecidos. Boekstegers et al. ${ }^{(9)}$ avaliando a $\mathrm{PO}_{2}$ nos músculos esqueléticos de pacientes sépticos, através de microsensores, demonstraram que a $\mathrm{PO}_{2}$, inclusive, aumenta, de acordo com a gravidade do processo. Este fato reforça o conceito de que a capacidade de utilização ou extração de oxigênio pelo tecido muscular estaria progressivamente comprometida, no curso da patologia.

Na medida em que o processo séptico evolui, outras disfunções podem progressivamente diminuir 
a oferta de oxigênio aos tecidos, tais como a síndrome de angústia respiratória do adulto (SARA), alterações da pressão arterial, depressão miocárdica e tromboembolismos, entre outros ${ }^{(10)}$.

A combinação destes fatores, seja por baixa extratividade tissular, pelo aumento da hidrólise de ATP ou pela diminuição da oferta de oxigênio, deslocam a curva de oferta consumo de oxigênio de forma característica. A partir destas curvas, Siggaard-Andersen et al. ${ }^{(11)}$ definem um ponto crítico, abaixo do qual se estabelece a chamada dependência oferta consumo.

Portanto, diversos distúrbios no metabolismo de oxigênio, na sepse, podem, potencialmente, provocar hipoxia, através de mecanismos distintos. A correção de cada fator requer medidas específicas. Utilizando-se a classificação para a hipoxia, proposta por Siggaard-Andersen, definem-se as distintas causas que podem comprometer o aporte de oxigênio aos tecidos, na sepse ${ }^{(12)}$.

\section{Radicais ativados do oxigênio, na sepse}

Apesar de o processo séptico ser quase que unanimemente reconhecido como uma espécie de "intoxicação por mediadores"(13), a formação de radicais livres do oxigênio constitui a etapa final, na ação dos vários sistemas que integram a resposta inflamatória. Nestas condições, as citocinas precipitam processos que produzem superóxido, peróxido de hidrogênio, radical hidroxila e seus derivados. Este uso não metabólico do oxigênio pode resultar em lesões celulares, diretas ou contribuir para a amplificação e perpetuação do processo inflamatório. As lesões oxidativas provocam a peroxidação de lipídeos, depleção de tióis essenciais e modificação de proteínas ${ }^{(2)}$.

O choque séptico está associado a disfunções de órgãos, que ocorrem dias após o evento inicial. Da variedade de distúrbios relacionados ao quadro, destaca-se a SARA e a falência de múltiplos órgãos. Há cumulativas evidências de que os radicais ativados desempenhem um papel decisivo nestas condições, tanto pela situação de distúrbios microcirculatórios, que provocam o fenômeno de isquemia e reperfusão, quanto por consequiências da própria resposta inflamatória. Dentre estas, destaca-se, na SARA, o papel dos neutrófilos, que, uma vez ativados, provocam lesões alveolares e endoteliais. Verificam-se, no plasma de pacientes sépticos, altos níveis de proteínas do neutrófilo (mieloperoxidase, elastase, alfa-1-proteinase oxidada). Ocorre, ainda, considerável depleção de antioxidantes plasmáticos, em pacientes com SARA e choque séptico ${ }^{(14)}$.

A produção de espécies reativas do oxigênio tem uma função imunológica vital, na ação de fagócitos ativados. Assim, monócitos, neutrófilos, eosinófilos e todos os tipos de macrófagos possuem sistemas enzimáticos específicos para a produção de radicais ati$\operatorname{vados}^{(15)}$. Na função dos neutrófilos, particularmente, a geração destas espécies é fundamental. Os polimorfonucleares se concentram em sítios específicos, atraídos por produtos bacterianos e citocinas. A destruição de bactérias ocorre por mecanismos oxigeniodependentes e processos que independem deste gás. Pacientes que apresentam distúrbios, no funcionamento de neutrófilos, por razões congênitas ou adquiridas, demonstram a relevância deste tipo de leucócito no sistema imunológico. São células muito ativas na resposta inflamatória e sua atuação destaca-se na patofisiologia de muitos processos, como a isquemia miocárdica, a sepse por Gram-negativos e a SARA ${ }^{(16)}$.

O neutrófilo em repouso consome muito pouco oxigênio, dependendo praticamente da glicólise anaeróbia para seu metabolismo. Quando ativado por estímulo apropriado, após cerca de um (1) minuto, esta célula altera rapidamente seu consumo de oxigênio, atingindo até cinquenta (50) vezes seu consumo basal. O consumo de glicose, através do "shunt" da via hexosemonofasfato, aumenta rapidamente.Ocorre, paralelamente, uma verdadeira descarga de superóxido e peróxido de hidrogênio, no meio. Por esta razão, esta rápida reação também é denominada irrupção respiratória ("respiratory burst"). Esta irrupção ocorre independentemente dos processos de fagocitose e degranulação, e é caracterizada por sua dependência à disponibilidade de oxigênio, como substrato ${ }^{(17)}$. $\mathrm{O}$ nível de produção de superóxido depende de tensões mínimas de oxigênio para ocorrer eficientemente (Ver Figura 1).

O excesso de radicais ativados pode provocar citotoxicidade, lesando lipídeos, proteínas ou o DNA. O sistema básico de defesa contra estes radicais é constituído por antioxidantes simples, que reagem diretamente com os radicais ou sistemas enzimáticos complexos, que os transformam. Destacam-se as superóxido dismutases que catalisam o superóxido em peróxido de hidrogênio, assim como a catalase e glutationa peroxidase, que transformam o peróxido em água. As reações regeneram o oxigênio ao seu estado normal ${ }^{(18,19)}$. 


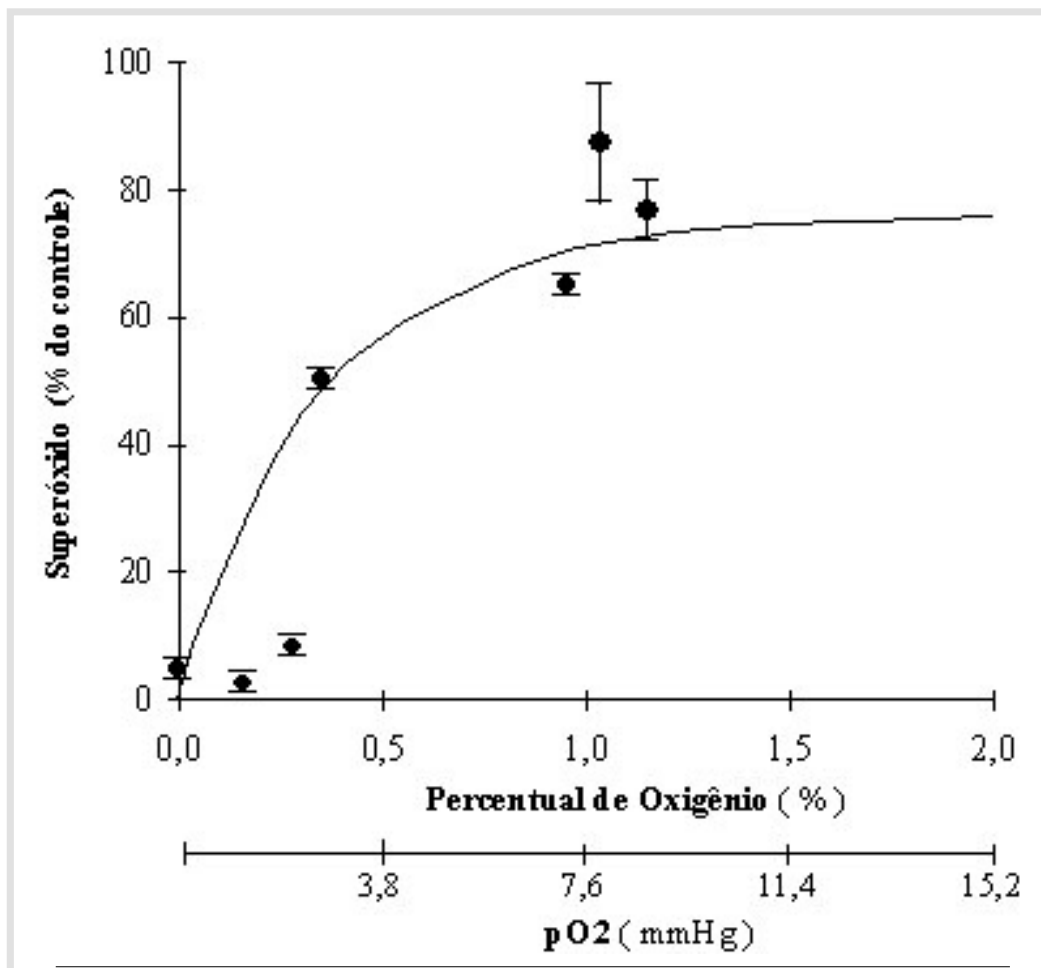

Figura 1 - Produção de superóxido em neutrófilos ativados.

A produção de espécies ativadas depende de tensões mínimas de oxigênio, definidas em percentual e pressão parcial de oxigênio. As ordenadas expressam o percentual de produção de superóxido em relação a controles, em ar ambiente $( \pm 160 \mathrm{mmHg})^{(17)}$.

No meio extracelular, macrófagos, neutrófilos e monócitos ativados amplificam a resposta a antígenos através de citocinas, liberando superóxido e óxido nítrico. O primeiro é precursor do peróxido de hidrogênio e o ácido hipocloroso. O segundo forma peroxinitrito que, além da ação oxidante, estimula outros macrófagos. No meio intracelular, os radicais podem se formar na própria mitocôndria ou no citoplasma. $\mathrm{O}$ peróxido, em presença de $\mathrm{Fe}$ [II], forma dióxido de nitrogênio ${ }^{(2)}$.

A ativação de neutrófilos é apontada como fator essencial no desenvolvimento da SARA, na sepse e no trauma ${ }^{(20)}$. Preparações isoladas de pulmão, perfundidas com neutrófilos ativados, provocam importantes alterações de permeabilidade capilar. $\mathrm{O}$ aquecimento prévio dos neutrófilos, a $48^{\circ} \mathrm{C}$, o que provoca a inativação da NADPH oxidase, previne as alterações endoteliais ${ }^{(21)}$. O uso de bloqueadores desta enzima demonstra resultados semelhantes ${ }^{(22)}$.

Neutrófilos de pacientes com sepse intra-abdominal, comparados com pacientes com cirurgias intestinais eletivas, apresentaram uma redução na expressão de receptores para TNF e IL-1 beta, em suas superfícies. O estímulo para irrupção respiratória, utilizando TNF ou IL-1 exógenos, diminui ainda mais o número de receptores. A produção de superóxido revelou-se comprometida nos neutrófilos do grupo séptico, havendo redução em sua capacidade de destruição de Candida albicans ${ }^{(23)}$.

Convém destacar que estudos de laboratório, ao contrário de estudos clínicos, permitem avaliar o processo séptico em suas fases mais precoces. A avaliação de pacientes, além de ser efetuada em geral, vários dias após a instalação do quadro, efetua-se em vigência de várias medidas terapêuticas, incluindo-se a antibioticoterapia. Vale lembrar que, nestes casos, são avaliados neutrófilos circulantes, e não os que estão aderidos a tecidos. Nos modelos experimentais, comprova-se uma potencialização na geração de radicais ativados por neutrófilos, assim como sua adesão e ativação, principalmente no fígado e pulmão. Desta forma, a ação mais intensa dos neutrófilos se dá em tecidos com maior concentração de citocinas e outros mediadores.

\section{Antioxidantes na sepse}

Estudos experimentais, em ratos, demonstraram que o tratamento prévio por três dias com o antioxidante alfatocoferol, melhora a sobrevivência dos animais na sepse induzida por punção e ligadura cecal. Já outros antioxidantes especiais, como o inibidor de peroxidação U7400F e um análogo do alfatocoferol, o U78517F, foram efetivos em melhorar a sobrevivência dos animais, mesmo quando administrados com a sepse instalada (24). Rose et al. ${ }^{(25)}$ também induziu sepse em ratos, administrando oito horas após superóxido dismutase (S.O.D.) A sepse induziu um importante aumento nas proteínas de fase aguda (PFA). A SOD diminuiu o lactato sérico, o estado febril e a mortalidade, não afetando a produção das PFA.

A presença de oligoelementos, geralmente metais de transição, está relacionada à produção ou inativação dos radicais livres. A adição de zinco em culturas de macrófagos peritoneais, de animais sépticos inibe a irrupção respiratória in vitro, demonstrando propriedades antioxidantes ${ }^{(26)}$. 
O acúmulo de neutrófilos, no espaço intersticial do pulmão, é um dos importantes fenômenos que cursam com a sepse. A endotoxina causa a liberação de substâncias no pulmão, que ativam e seqüestram neutrófilos, como proteínas de adesão endotelial e citocinas. A potencial ação protetora, exercida pelos corticóides, levou ao desenvolvimento e pesquisa de outros agentes específicos, como o ibuprofen, um potente inibidor da cicloxigenase. O mesmo reduz a produção de metabólitos do ácido aracdônico, como a prostaciclina e o tromboxano. Em vários estudos relativos ao trauma, sepse e grandes queimados, o ibuprofen demonstrou-se igualmente eficaz na prevenção de lesões induzidas por radicais ativados do oxigênio ${ }^{(27)}$.

Uma das ações do ibuprofen consiste em limitar a produção de radicais ativados pelos neutrófilos ${ }^{(28)}$. Considerando as alterações que estes radicais induzem na permeabilidade vascular, especialmente pulmonar, verifica-se a a diminuiçào da complacência pulmonar e o acúmulo de líquido extravascular no pulmão de animais sépticos. Estas alterações são abolidas pelo uso de ibuprofen, mas não no grupo tratado com cimetidina ${ }^{(29)}$.

\section{Bases do uso da hiperoxigenação hiperbárica em infecções}

Em condição hiperbárica, destaca-se a ação do oxigênio como droga. Alguns mecanismos são de particular interesse medicinal, como a ação microbicida ou microbiostática direta ou indireta, a ação bioquímica em reações que o oxigênio possa deslocar substâncias tóxicas, efeitos fisiológicos, específicos e o efeito sinérgico, com drogas. O efeito mecânico da pressão per se apresenta valor terapêutico direto apenas em casos de embolia gasosa ou patologias disbáricas, como a doença descompressiva. O principal potencial de tratamento reside no aumento notável da tensão de oxigênio em todos os líquidos corporais, uma vez que valores de até $1800 \mathrm{mmHg}$ podem ser atingidos, quando se respira oxigênio a $100 \%$ em uma pressão de três vezes a atmosfera normal (3 ATA). Nesta condição, cerca de 6,4 ml de oxigênio estarão dissol- vidos em cada $100 \mathrm{ml}$ sangüíneos, além do conteúdo ligado à hemoglobina.

\section{Tensão de oxigênio tissular em hiperoxia hiper- bárica}

Expondo-se o organismo a uma pressão ambiente superior à normal, a pressão parcial dos gases, nos alvéolos pulmonares, aumentará proporcionalmente. Considerando a pressões parciais do dióxido de carbono $\left(\mathrm{P}_{\mathrm{A}} \mathrm{CO}_{2}\right)$ e vapor de água $\left(\mathrm{PH}_{2} \mathrm{O}\right)$ existentes nos alvéolos, a pressão parcial de oxigênio poderá ser calculada facilmente (Tabela I ).

A partir das pressões parciais de oxigênio, atingidas em hiperoxia hiperbárica, da mesma forma pode-se calcular o aumento no conteúdo de oxigênio dissolvido no sangue arterial. A Tabela II apresenta este aumento no conteúdo arterial de oxigênio, em acréscimos percentuais, para várias concentrações de hemoglobina. Desta maneira, pode-se afirmar, por exemplo, que pacientes com hemoglobina de $10 \mathrm{~g} / \%$, expostos a hiperoxia hiperbárica, entre 2 e 3 ATA (atm abs), apresentam um aumento de 30 a $47 \%$ no conteúdo arterial de oxigênio.

Considerando-se a soma das frações de oxigênio carreadas pela hemoglobina e a dissolvida, para uma extração de oxigênio constante, pode-se observar que, em hiperoxia hiperbárica, o sangue venoso ainda apresenta um conteúdo substancial de oxigênio. Comparando-se as condições de normoxia e hiperoxia hiperbárica, a 3 ATA, a hemoglobina, no sangue venoso, ainda permanece praticamente saturada.

\begin{tabular}{|cccc|}
\hline \multicolumn{4}{|c|}{ Tabela I- Pressão alveolar de oxigênio } \\
\hline Pressẫo & $\mathrm{Ambiente}$ & $\mathrm{PAO}_{2}-\mathrm{AR} / 0,21$ & $\mathrm{PAO}_{\mathrm{A}}-\mathrm{O} 2 / 1,00$ \\
\hline $\mathrm{ATA}($ () & $\mathrm{MmHg}$ & $\mathrm{MmHg}$ & $\mathrm{MmHg}$ \\
\hline 1,0 & 760 & 102 & 673 \\
1,5 & 1140 & 182 & 1053 \\
2,0 & 1520 & 262 & 1433 \\
3,0 & 2280 & 422 & 2193 \\
4,0 & 3040 & 582 & Nẫo se utiliza \\
\hline
\end{tabular}

(*) A denominamação ATA, comumente empregada em medicina hiperbárica, equivale a atmosferas absolutas (atm abs).

A $P_{A} \mathrm{O}_{2}$ indica a pressão alveolar de oxigênio atingida em condições hiperbáricas. Os valores de pressão ambiente encontram-se em atmosferas absolutas (atm abs ou ATA), onde 1 ATA $=760 \mathrm{mmHg}$, ao nível do mar. Valores deduzidos da equação do ar alveolar a $37^{\circ} \mathrm{C}$, com $\mathrm{P}_{\mathrm{A}} \mathrm{CO}_{2}=40 \mathrm{mmHg}, \mathrm{PH}_{2} \mathrm{O}=47 \mathrm{mmHg}, \mathrm{R}=0,8$ (AR) e $\mathrm{R}=1,0$ (O2). $P_{A} \mathrm{O}_{2}$ em ar ambiente (FiO2=0,21) e oxigênio puro (FiO2=0,21). O oxigênio hiperbárico não é utilizado acima de 3 ATA. Adaptado de IAZZETTI \{\#180\}. 


\begin{tabular}{|c|c|c|c|c|c|c|c|}
\hline \multicolumn{8}{|c|}{ Tabela II - Conteúdo de oxigênio dissolvido no sangue arterial } \\
\hline \multicolumn{2}{|c|}{ Pressấo Ambiente } & \multicolumn{2}{|c|}{$\begin{array}{l}\text { Conteúdo de } \mathrm{O}_{2} \\
\text { Dissovido }(\mathrm{ml} \%)\end{array}$} & \multicolumn{4}{|c|}{$\begin{array}{l}\text { Acréscimo no conteúdo } \mathrm{O}_{2} \text { arterial. } \\
\text { em relacẫo à hemoulobina }(\mathrm{a} \%)\end{array}$} \\
\hline ATA & $\mathrm{MmHg}$ & $\mathrm{FiO}_{2}=0,21$ & $\mathrm{FiO}_{2}=1,00$ & 15 & 10 & 8 & 6 \\
\hline 1 & 760 & 0,32 & 2,09 & $8,8 \%$ & $13,0 \%$ & $16,2 \%$ & $21,4 \%$ \\
\hline 2 & 1520 & 0,81 & 4,44 & $20,0 \%$ & $30,0 \%$ & $37,4 \%$ & $49,0 \%$ \\
\hline 3 & 2280 & 1,31 & 6,80 & $32,2 \%$ & $47,5 \%$ & $59,1 \%$ & $78, \pi \%$ \\
\hline
\end{tabular}

Aumento percentual em relação à pressão ambiente e com diferentes concentrações de hemoglobina. Assumindo-se $37^{\circ} \mathrm{C}$; $\mathrm{pH}=7,4$; sem "shunt" pulmonar. Um grama de hemoglobina transporta 1,34 ml/O2. A cada $1 \mathrm{mmHg}$ da PaO2, dissolvem-se 0,0031 vol/\% complementares no sangue. Adaptado de IAZZETTI \{\#180\}.

Portanto, haverá um maior conteúdo de oxigênio dissolvido em todos os liquidos corporais, cuja principal implicação biofísica é permitir um considerável aumento da distância máxima de difusão entre o centro do capilar e os tecidos.

\section{Alterações hemodinâmicas}

A hiperóxia hiperbárica tem efeito vasoconstritor, peculiar, na maioria dos tecidos. O fluxo sangüíneo diminui no tecido quase que proporcionalmente ao consumo basal que determinado tecido apresente. Em geral, tecidos de menor metabolismo apresentarão maior diminuição de fluxo. Assim, reduz-se de 20-25\% do fluxo cerebral e $33 \%$ do consumo renal, em 2 ATA. Efeitos que se devem ao controle vasomotor intrínseco, havendo pouca influência dos mecanismos centrais. De maneira geral, ocorre uma vasoconstrição generalizada, sendo exceção a circulação pulmonar, uma vez que a hiperoxia hiperbárica provoca importante vasodilatação dos vasos pulmonares. Após 15 min. a 3 ATA, ocorre uma diminuição de $30 \%$ na pressão da artéria pulmonar. Prevalece a vasoconstrição, em maior ou menor grau conforme o tecido, provocando um efeito global de aumento da resistência periférica. Com isto, desloca-se volemia para os vasos de capacitância, diminuindo o retorno venoso. A hiperoxia induz ainda certa diminuição da frequiência cardíaca. Da combinação destes dois fatores resulta um débito cardíaco reduzido, da ordem de $20-30 \%$ a 3 ATA. Desta forma, embora a resistência periférica total esteja aumentada, a pressão arterial é mantida, considerando-se uma diminuição proporcional do débito cardíaco. Necessário ressalvar que esta vasoconstrição e diminuição do débito cardíaco, ocorrem apenas quando o aporte de oxigênio aos tecidos torna-se excessivo, portanto não sendo possível ocorrer isquemia, enquanto os mecanismos de autoregulação vasculomotores estiverem preservados ${ }^{(30)}$. Esta característica é singular, uma vez que a indução de vasoconstrição com aumento do aporte de oxigênio é uma situação muito especial. Isto confere uma ação antiedematogênica específica ao oxigênio hiperbárico, particularmente útil em situações como edema cerebral e síndrome compartimental.

\section{Alterações do metabolismo oxidativo}

Ocorrem, no metabolismo, várias reações próoxidantes e antioxidantes que devem ser mantidas em um cuidadoso equilíbrio, impedindo que o excesso de oxidação ou o comprometimento do sistema de proteção antioxidante possam resultar em lesões a células íntegras. A maior concentração de oxigênio, proporcionada pela hiperoxia hiperbárica em todos os tecidos, implica, necessariamente, em um aumento do substrato oxidante disponível para as reações deste tipo. A exposição do organismo às altas tensões de oxigênio, obtidas em hiperoxia hiperbárica, aumenta a formação de radicais ativados do oxigênio e estimula os sistemas antioxidantes. Ocorrem os mesmos distúrbios da exposição prolongada ao oxigênio a $100 \%$, em pressão normal, no entanto, de forma mais rápida e pronunciada, como na intoxicação pulmonar. Há, ainda, efeitos tóxicos peculiares, que não ocorrem em hiperoxia normobárica, como efeitos neurológicos. Vale lembrar que grande parte do oxigênio no organismo está ligado à hemoglobina ou em trânsito por breve período. Além dos alvéolos pulmonares, este gás ocorre, de forma livre, nos tecidos, uma vez que o gradiente capilar tecido é consideravelmente aumentado, atingindo até $6,4 \mathrm{ml} / \mathrm{dl}$ a 3 ATA. A maior concentração global de oxigênio molecular em todo o organismo e a disponibilidade de substratos biológicos 
capazes de reagir com o mesmo, podem, potencialmente, aumentar a produção de radicais ativados em todo o organismo. Vale ressaltar que, fora do compartimento intravascular, o oxigênio só ocorre na forma livre apenas em seu curto trajeto entre o capilar e as mitocôndrias.

\section{Tensão de oxigênio e crescimento microbiano}

A tensão de oxigênio desempenha um papel crítico no desenvolvimento de infecções. Várias condições patológicas, como lesões ou infecções, podem diminuir notavelmente a tensão de oxigênio no sítio afetado; o fluido de lesões experimentais, frequentemente apresenta valores inferiores a $10 \mathrm{mmHg}$, em infecções ósseas experimentais verifica-se reduções de $50 \%$ das tensões normais ${ }^{(1)}$. Portanto, condições de considerável hipóxia, ou mesmo anaerobiose, são verificadas em tecidos orgânicos infectados, favorecendo o crescimento de bactérias específicas. A princípio, é nestas infecções que a hiperoxia hiperbárica apresenta maior potencial terapêutico.

A sensibilidade bacteriana em relação à tensão de oxigênio é variável, dependendo de vários fatores. Tensões de oxigênio acima de $4 \mathrm{mmHg}$ são bactericidas para anaeróbios estritos. Anaeróbios aerotolerantes podem suportar níveis de até $60 \mathrm{mmHg}$. Em níveis equivalentes à normoxia, observa-se ação bactericida contra Peptococcus magnus (Peptoestreptococo), Bacteroides fragilis e Clostridium perfringens. A sensibilidade varia notavelmente entre espécies semelhantes, como, por exemplo, o Clostridium septicum, que é $50 \%$ menos suscetível que o Clostridium tetani, e depende do estágio de desenvolvimento do ciclo da bactéria. Embora esporos de Clostridium perfringens não sejam destruídos em hiperoxia hiperbárica, não ocorre germinação dos mesmos, nestas condições.

Anaeróbios facultativos e aeróbios obrigatórios são resistentes, in vitro, à hiperoxia hiperbárica, de maneira geral. Apenas exposições muito prolongadas (24 hs a 3 ATA) demonstram-se bactericidas para Pseudomonas aeruginosa, Proteus vulgaris e Salmonella typhi, em meio de triptcaseína, observando-se para os mesmos, no entanto, uma ação bacteriostática a partir de tensões de oxigênio de $1,5 \operatorname{ATA}^{(1)}$.

Os microorganismos aeróbios, obrigatórios ou anaeróbios, facultativos exibem um padrão caracteristicamente bifásico, havendo uma tensão de oxigênio ideal para o seu crescimento, após o que ocorre uma inibição bacteriostática em relação a controles expostos a condições ambiente, superadas as defesas antioxidantes da bactéria; ver Figura 2 e Tabela III.
Figura 2 - Crescimento de Escherichia coli e Pseudomonas sp "in vitro". Utilizaram-se várias tensões de oxigênio para culturas com inóculo inicial padronizado. A seta assinala a tensão em que a Escherichia coli passa a ser inibida abaixo do valor do controle. Adaptado de Ollodart et al. ${ }^{(31)}$. 


\begin{tabular}{|lccccc|}
\hline \multicolumn{7}{|c|}{ Tabela III - Inibição bacteriana "in vitro" por OHB } \\
\multicolumn{1}{|c}{ Espécie } & Ambiente & OHB & Vezes & OHB & Vezes \\
& 0,21 ATA & 2 ATA & Ambiente & 3 ATA & Ambiente \\
\hline Clostridium perfringens & 5 & 13 & 2,6 & 15 & 3,0 \\
Clostridium histolyticum & 6 & 15 & 2,5 & 17 & 2,8 \\
Clostridium butyricum & 8 & 16 & 2,0 & 18 & 3,0 \\
Clostridium sporogenes & 9 & 19 & 2,1 & 22 & 2,4 \\
Vellionela sp & 10 & 23 & 2,3 & 29 & 2,9 \\
Micrococcus niger & 16 & 22 & 1,4 & 24 & 1,5 \\
Ristella fraqilis & 13 & 29 & 2,2 & 28 & 2,2 \\
\hline
\end{tabular}

Zona de inibição de crescimento, in vitro, de diversas bactérias anaeróbias em relação a pressão de oxigênio no meio $(0,21$ ATA $=160 \mathrm{mmHg} ; 2$ ATA $=1520 \mathrm{mmHg} ; 3$ ATA $=2280 \mathrm{mmHg}$ ). Assinala-se o aumento da zona de inibição, proporcionado em hiperoxia hiperbárica. Adaptado de FREDETTE et al. ${ }^{(32)}$.

- Inibição de transporte em membranas - Através do comprometimento na captação de precursores para a transcrição de mRNA. A hiperoxia diminui a captação de lactose e guanosina na Escherichia coli. A oxidação de proteínas de transporte que contenham o grupo sulfidril, efeito típico do ânion superóxido, também compromete a captação de substratos.

- Inibição da síntese e degradação de DNA - Lesões diretas ao RNA e DNA são induzidas por radicais ativados do oxigênio. $\mathrm{O}$ oxigênio, em níveis normobáricos, inibe a transcrição de RNA em Bacteroides sp. A exposição da Escherichia coli à hiperoxia inibe seu crescimento e aumenta a atividade da endonuclease IV (enzima reparadora de DNA).

Embora a avaliação in vitro seja indispensável para a avaliação microbiológica, do ponto de vista clínico, a sensibidade bacteriana deve ser avaliada in vivo, através de estudos de terapêutica experimental. Nestas condições, pode-se avaliar, concomitantemente, as ações do sistema imunológico e das tensões efetivas de oxigênio, em cada tecido in vivo. Como exemplo de um modelo apropriado, destaca-se, na Figura 3, o resultado de hemoculturas seriadas, de cães que receberam inóculo de material fecal intraperitoneal, tratados ou não em hiperoxia hiperbárica, e as hemoculturas seriadas obtidas $^{(31)}$.

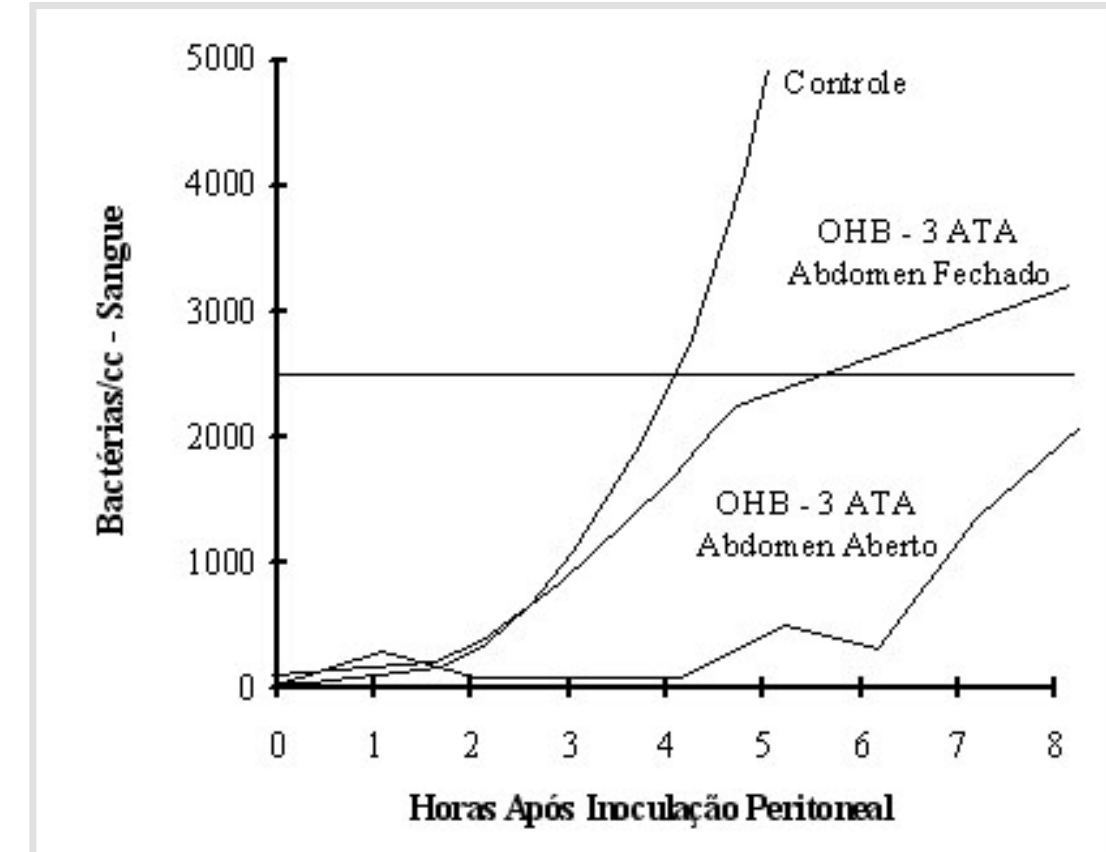

Figura 3 - Hemoculturas quantitativas na peritonite fecal. Após administração de inóculo fecal, na cavidade peritoneal de cães. Grupo controle em ar ambiente ( $n=13)$, grupo tratado com OHB a 3 ATA, $(n=10)$ e grupo tratado com OHB a 3 ATA, com o abdômen aberto $(n=10)$, uma hora após inoculação. Adaptado de Ollodart et al.(31). 
Limites de exposição e efeitos tóxicos: Com o aumento da produção de radicais ativados, vários tecidos apresentam-se mais suscetíveis de apresentar lesões oxidativas, decorrendo disfunções evidentes. Além do efeito tóxico pulmonar, o sistema nervoso central pode apresentar importantes alterações. Por isto, a pressão e períodos de exposicão à $\mathrm{OHB}$ são limitados por curvas de segurança bem definidas ${ }^{(30)}$.

\section{Uso clinico da OHB em infecções}

Clinicamente, a oxigenoterapia hiperbárica é utilizada no tratamento de infecções necrotizantes de tecidos moles (INTM), incluindo-se celulites, fasciítes ou miosites necrotizantes. O uso combinado de cirurgia, antibióticos e OHB é eficaz no tratamento da gangrena gasosa ${ }^{(33)}$, doença de Fournier ${ }^{(33,34)} \mathrm{e}$ infecções secundárias por estreptococos anaeróbios ${ }^{(35)}$. Certas localizações destas INTM tornam, por vezes, muito dificultosa a própria ressecção cirúrgica, radical, dos tecidos moles afetados, como, por exemplo, em celulites cervicais extensas ${ }^{(36)}$; ou toráxicas ${ }^{(37)}$. O debridamento cirúrgico de tecidos infectados, mesmo em casos crônicos, quando o processo é extenso ou refratário, apresenta melhor resolução quando conjugado à $\mathrm{OHB}^{(38)}$. Pode-se exemplificar tal fato, com osteomielites crônicas, refratárias ou agudas, de localização crítica e difícil solução cirúrgica, como as que ocorrem em ossos cranianos ${ }^{(39)}$ e com complicações de infecções micóticas, como a mucormicose rinocerebral $^{(40)}$. No Serviço de Medicina Hiperbárica do HCUNICAMP, há mais de seis anos, os casos de infecções necrotizantes de tecidos moles são tratados como rotina, seja como patologias primárias (p.e. Doença de Fournier e Fasciítes Necrotizantes, geralmente referidas pela Cirurgia do Trauma) ou secundárias (outros processos infecciosos, cirurgias radicais, radioterapia, pós-escaras de decúbito extensas e outros agravantes; referidos pela Cirurgia Vascular, UTI, Ortopedia e serviços de Oncologia).

Quando o paciente com uma destas infecções agudas é destinado à oxigenoterapia hiperbárica, não raro a infecção está em estágio avançado, cursando com sepse. As reações do organismo exposto à hiperoxia hiperbárica, nestas condições, ainda assim, não estão devidamente caracterizadas. A experiência clínica refere-se principalmente a infecções por anaeróbios ou mistas, que envolvem a liberação de exotoxinas, cujo exemplo clássico é a gangrena gasosa. São ainda mais limitadas as informações sobre exposição de pacientes com sepse de origem pulmonar e intra-abdominal.
Pela multiplicidade de mecanismos anteriormente descritos para a sepse e hiperoxigenação hiperbárica, supõe-se que a interação destas condições apresente, potencialmente, alguns efeitos favoráveis, assim como consequiências deletérias. Pela revisão efetuada, com relação à interação da $\mathrm{OHB}$ e o processo séptico, destacam-se muitos aspectos.

A maioria dos trabalhos disponíveis sobre a interação da hiperoxia hiperbárica, em infecções e sepse, concentra-se em estudos de mortalidade, microbiológicos e de terapêutica experimental ${ }^{(33)}$. Alguns estudos avaliam alterações fisiológicas que cursam com o processo $^{(41)}$.

Dos componentes assinalados ressalta-se a importância de pesquisas clínicas e experimentais sobre a forma pela qual a hiperoxigenação hiperbárica interfere no metabolismo oxidativo energético e não energético, na sepse. Na oxidação energética (respiração), destaca-se o potencial de uma compensação transitória da hipoxia, que ocorre por vários mecanismos, na sepse. Quanto aos processos oxidativos não energéticos, devem ser consideradas possibilidades terapêuticas, como a potencialização da ação de granulócitos, efetores vitais de defesa imunológica, e o estímulo à produção de enzimas antioxidantes, aumentando a resistência de tecidos íntegros aos radicais ativados. Se, por um lado, isto favoreceria a imunidade inespecífica, potencializando os processos antibacterianos de fagócitos, que dependem do oxigênio, por outro, poderiam ser reforçadas lesões induzidas por espécies ativadas. Assim, a oxidação tissular poderia exacerbar-se, incluindo-se danos provocados por neutrófilos no pulmão e fígado ou, ainda, pelos fenômenos de isquemia e reperfusão, que cursam com o processo séptico.

Admite-se que, na sepse, o equilíbrio oxidativo esteja comprometido, favorecendo os processos pró-oxidativos. As células do sistema imunológico, notadamente macrófagos e neutrófilos ativados, desempenham um papel decisivo neste tipo de lesão endotelial e parenquimatosa em vários tecidos, destacando-se o pulmão, o fígado e o mesentério. Em outros tecidos, como no músculo esquelético, a própria isquemia pode induzir disfunções mitocondriais que levam à formação excessiva de peróxido de hidrogênio e à atenuação de enzimas antioxidantes ${ }^{(42)}$. Modelos experimentais e culturas celulares acumulam evidências consideráveis do papel destas espécies intermediárias de oxigênio, na fisiopatologia da sepse. Estudos clínicos e o uso experimental de bloquea- 
dores da formação de radicais do oxigênio, indicam que este é um aspecto de grande potencial na futura terapêutica da sepse ${ }^{(43)}$.

A endotoxina aumenta a resistência pulmonar aos efeitos tóxicos do oxigênio. Porém, a ação conjunta de endotoxina e hiperoxia hiperbárica deve ser examinada. O óxido nítrico, que se revelou um importante mediador na intoxicação neurológica pelo oxigênio, tem produção excessiva na sepse, podendo potencializar esta ação nociva da $\mathrm{OHB}^{(44)}$.

Portanto, há vários pontos a serem esclarecidos na interação da sepse e hiperoxia hiperbárica, especialmente em infecções por Gram-negativos. Questões que determinam algumas linhas principais de investigação, em modelos experimentais e protocolos clínicos, no uso de OHB, em infecções graves:

- potencial bactericida e bacteriostático in vivo;

- grau de compensação intermitente da hipoxia em tecidos específicos;

- alterações fisiológicas (hemodinâmicas, pulmonares, endócrinas) durantes as fases hiper e hipodinâmicas;

- interferência na resposta imunológico e inflamatória nos vários estágios do processo;

- efeitos no metabolismo oxidativo energético e não energético, nos orgãos e tecidos mais afetados.

Em linha de pesquisa que estamos desenvolvendo, já há alguns anos na UNICAMP, a partir de um modelo de sepse experimental, em ratos, induzida por ligadura e punção cecal (LPC), verificamos uma sensível diminuição de mortalidade entre grupos de animais com peritonite fecal, expostos ou não à hiperoxigenação hiperbárica ${ }^{(45)}$.

Estendendo a investigação aos fatores envolvidos nesta resposta, estudamos parâmetros hematológicos, microbiológicos e imunológicos, na exposição de animais sépticos à OHB. Em síntese, além de hemoculturas seriadas e estudos hematológicos, efetuamos dosagens plasmáticas dos seguintes mediadores: TNF, "Tumor Necrosis Factor", (imunoensaio tipo ELISA); nitrato e nitrito, catabólitos do óxido nítrico, (HPLC, "High Performance Liquid Cromatography") e corticosterona (radioimunoensaio), até doze horas de pós-operatório. Duas sessões (2 ATA, 120 min) efetuadas uma e seis horas após a cirurgia, permitiram uma diminuição significativa da taxa de mortalidade, de $75 \%$ (LPC em ar ambiente) para $25 \%$ (LPC tratado com $\mathrm{OHB}$ ), em vinte e quatro (24) horas. A OHB não alterou os tipos de bactérias identificadas em hemoculturas, nem a proporção de animais com culturas positivas. As bactérias mais freqüentes foram a Escherichia coli e Bacteroides sp.

O número de animais com bacteremia positiva, a maioria doze horas pós-LPC, não se revelou um fator prognóstico consistente. Seis horas pós-LPC ocorreu considerável trombocitopenia e leucopenia, verificando-se redução nos neutrófilos e linfócitos circulantes, sem alterações nos monócitos, sugerindo um seqüestro de leucócitos específicos. Doze horas pósLPC, houve recuperação significativa na contagem de neutrófilos, no grupo exposto à $\mathrm{OHB}$, apesar de a maioria dos animais apresentarem-se bacterêmicos. O nível plasmático de TNF mostrou considerável variação individual, não havendo diferenças significativas entre os grupos, incluindo-se animais do grupo controle. A corticosterona apresentou-se elevada em todos os grupos, mantendo um alto e estável patamar entre seis e doze horas, com um valor de cinco vezes o normal, também sem diferenças expressivas entre os grupos. A sepse não justificou este aumento, uma vez que animais do grupo controle também apresentaram doses elevadas do corticóide, indistinguíveis dos grupos sépticos. Houve um aumento do óxido nítrico plasmático em animais sépticos não tratados, o que não ocorreu naqueles expostos à $\mathrm{OHB}$.

Os resultados sugerem maior competência imunológica no grupo exposto à $\mathrm{OHB}$, manifestada por menores níveis de mortalidade, seqüestro de neutrófilos e catabólitos do óxido nítrico, após doze horas de infecção. Como mecanismo protetor mais provável, neste modelo, reforçaram-se as evidências de uma ação bacteriostática da OHB. Por outro lado, não foram verificados efeitos deletérios da OHB sobre os fatores analisados. Evidenciam-se a cinética dos neutrófilos e a dosagem de óxido nítrico sangüíneo como fatores importantes na fisiopatologia da sepse, neste modelo. A literatura recente destaca o papel da adesão e ativação de neutrófilos no desenvolvimento de disfunções de órgãos e, ainda, do óxido nítrico, na hipotensão refratária que determina o choque séptico ${ }^{(46)}$.

A particular ação da OHB, nestes processos, deve ser eluciada em um esforço conjunto entre vários centros de pesquisa, acrescentando novas informações na fisiopatologia do processo séptico e definindo parâmetros para um uso clínico mais eficaz e controlado desta terapêutica, permitindo, inclusive, ampliar sua utilização no quadro séptico, além das aplicações tradicionais nas infecções necrotizantes de tecidos moles. 


\section{Apêndice}

Excerto do parecer do Conselho Regional de Medicina do Estado de São Paulo - Resolução CREMESP N. 58 / 95 (1995) :

“.....Parágrafo 4. As aplicações clínicas reconhecidas da oxigenoterapia hiperbárica são as seguintes:

4.1. Embolias Gasosas

4.2. Doença Descompressiva

4.3. Embolia Traumática pelo Ar

4.4. Envenenamento por monóxido de carbono ou intoxicação por fumaça

4.5. Envenenamento por cianeto ou derivados cianídricos

4.6. Gangrena Gasosa Clostridiana

4.7. Síndrome de Fournier

4.8. Outras infecções necrotizantes de tecidos moles: celulites, fasciítes e miosites.

4.9. Isquemias Agudas Traumáticas: lesão por esmagamento, síndrome compartimental, reimplantação de extremidades amputadas e outras.

4.10. Vasculites agudas de etiologia alérgica, medicamentosa ou por toxinas biológicas (aracnídeos, ofídios e insetos)
4.11. Queimaduras térmicas ou elétricas

4.12. Lesões Refratárias: úlceras de pele, pé diabético, escaras de decúbito, úlceras por vasculites auto-imunes, deiscências de suturas.

4.13. Lesões por Radiação: radiodermite, osteorradionecrose e lesões actínicas de mucosas de risco

4.14. Retalhos ou enxertos comprometidos ou

4.15. Osteomielites

4.16. Anemia aguda nos casos de impossibilidade de transfusão sangüínea. ...."

\section{Agradecimentos}

O trabalho experimental que estamos desenvolvendo é primariamente efetuado no Núcleo de Medicina e Cirurgia Experimental da UNICAMP, onde montamos e operamos uma câmara hiperbárica experimental. $\mathrm{O}$ tratamento de pacientes é efetuado na câmara multipaciente SR-10 do Serviço de Medicina Hiperbárica do Hospital de Clínicas da UNICAMP. Não seria possível o desenvolvimento desta linha de trabalho sem a estreita colaboração de vários professores do Departamento de Cirurgia e outros docentes da Faculdade de Ciências Médicas e do Instituto de Biologia da UNICAMP.

IAZZETTI PE \& MANTOVANI M. Hyperbaric hyperoxia in severe infections and sepsis - Concepts and perspectives. Medicina, Ribeirão Preto, 31: 412-423, july/sept. 1998.

ABSTRACT: We did a review, considering the relevant factors that could play a role in using hyperbaric oxygen therapy in sepsis. Specially in intra-abdominal infecctions due to gut Gram negative bacteria, stressing upon its interest to clinical and laboratory research. Some concepts related to hypoxia and oxidative metabolism are described, reviewing the role of oxygen free radical (reactive oxygen species or ROS) and anti-oxidants in sepsis development. The clinical use of HOT and in the clinical setting, and its potential in severe infections, are discussed.

UNITERMS: Hyperbaric Oxygenation. Infection. Sepsis.

\section{REFERÊNCIAS BIBLIOGRÁFICAS}

1 - PARK MK; MYERS RAM \& MARZELLA L Oxygen tensions and infections: modulation of microbial growth, activity of antimicrobial agents, and immunologic responses. Clin Infect Dis 14: 720-740, 1992.

2 - TAYLOR DE \& PIANTADOSI CA Oxidative metabolism in sepsis and sepsis syndrome J Crit Cares 10: 122-135, 1995.

3 - MIZOBATA Y et al. The duration of infection modifies mitochondrial oxidative capacity in rat skeletal muscle.; J Surg Res 59: 165-173, 1995.
4 - LEHNINGER AL. O ciclo de ácidos tricarboxílicos. In: LEHNINGER AL. Fundamentos de bioquímica. Sarvier, São Paulo, p. 215-235, 1977.

5 - FRIEDMAN G et al. Combined measurements of blood lactate concentrations and gastric intramucosal $\mathrm{pH}$ in patients with severe sepsis. Crit Care Med 23: 1184-1193, 1995.

6 - VINCENT JL. Oxygen transport in severe sepsis; Acta Anaesthesiol Scand 37: 29-31, 1993. Suppl 98.

7 - VINCENT JL \& DE BACKER D. Oxygen uptake - Oxygen supply dependency : Fact or fiction? Acta Anaesthesiol Scand 39: 229-237, 1995. Suppl 107. 
8 - MIZOBATA $Y$ et al. The duration of infection modifies mitochondrial oxidative capacity in rat skeletal muscle. J Surg Res 59: 165-173, 1995.

9 - BOEKSTEGERS $P$ et al. Skeletal muscle partial pressure of oxygen in patients with sepsis. Crit Care Med 22: 640-650, 1994.

10 - HOTCHKISS RS \& KARL IE. Reevaluation of the role of cellular hypoxia and bioenergetic failure in sepsis. JAMA 267: 1503-1510, 1992.

11 - SIGGAARD ANDERSEN O; ULRICH A \& GOTHGEN IH. Classes of tissue hypoxia, Acta Anaesthesiol Scand 39: 137-142, 1995. Suppl. 107.

12 - SIGAARD ANDERSEN $O$ et al. Oxygen status of arterial and mixed venous blood; Cri Care Med 23: 1284-1293, 1995.

13 - WENDEL A. Reactive oxygen species, antiproteases, and cytokines in sepsis. Klin Wochenschr 69: 969-974, 1991.

14 - PINCEMAIL J. Free radical in human diseases. In: FAVIER $A E$ et al . Analysis of free radicals on biological systems, Birkhauser Verlag, Basel, p. 83-98, 1995.

15 - HALLIWELL B. Reactive oxygen species in living systems: source, biochemistry, and role in humam disease. Am J Med 91: 14-22, 1991. Suppl 3C.

16 - SAWYER DW; DONOWITZ GR \& MANDELL GL. Polymorphonuclear neutrophils: an effective antimicrobial force. Rev Infect Dis 11: S1532-1544, 1989. Suppl 7.

17 - BABIOR BM. The role of active oxygen in microbial killing by phagocytes. In: POMEROY A. Pathology of oxygen, Academic Press, London, p. 45-58, 1982.

18 - FREEMAN BA \& CRAPO JD. Biology of disease - Free radicals and tissue injury ; Lab Inv 47: 412-422, 1982.

19 - HALLIWELL B. \& GUTTERIDGE JMC. Oxygen is poisonous. In: HALLIWELL B., ed. Free radicals in biology and medicine, Clarendon Press, Oxford, p. 1-21, 1989.

20 - KOIKE K et al. Gut ischemia mediates lung injury by a xanthine oxidase-dependent neutrophil mechanism. J Surg Res 54: 469-473, 1993.

21 - GUIDOT DM et al. Inhaled nitric oxide prevents neutrophilmediated, oxygen radical-dependent leak in isolated rat lungs. Am J Physiol, 269(1 Pt 1): L2-5, 1995

22 - HAMPTON MB \& WINTERBOURN CC. Modification of neutrophil oxidant production with diphenyleneiodonium and its effect on bacterial killing. Free Radic Biol Med, 18: 633-639, 1995.

23 - SIMMS HH \& D'AMICO R. Intra-abdominal sepsis alters tumor necrosis factor-alpha and interleukin-1 beta binding to human neutrophils. Crit Care Med 20: 11-16, 1992.

24 - POWELL RJ et al. Effect of oxygen-free radical scavengers on survival in sepsis. Am Surg 57: 86-88, 1991.

25 - ROSE S et al. Diltiazem and superoxide dismutase modulate hepatic acute phase response in gram-negative sepsis. Shock 1: 87-93, 1994.

26 - SRINIVAS U; JEPPSSON B \& BRACONIER JH. Superoxide production of peritoneal macrophages in experimental gram-negative sepsis; influence of in vitro and in vivo supplements of zinc. APMIS 97: 682-688, 1989.

27 - ROCKWELL WB \& EHRLICH HP. Ibuprofen in acute-care therapy. Ann Surg 211: 78-83, 1990
28 - CAREY PD et al. The neutrophil respiratory burst and tissue injury in septic acute lung injury: the effect of cyclooxygenase inhibition in swine. Surgery 112: 45-55, 1992.

29 - ZIMMERMAN JJ. Oxyradical pathogenesis in sepsis. In: LAMY M \& THIJS LG,eds. Mediators of sepsis, SpringerVerlag, Berlin; p. 1752-1756, 1995.

30 - IAZZETTI PE. Hiperoxigenação hiperbárica. In: TERZI RGG, ed. Equilibrio ácido-básico e transporte de oxigênio, Editora Manole, São Paulo, p. 180-204, 1992

31 - OLLODART R \& BLAIR E. High pressure oxygen as an adjunct in experimental bacteremic shock. JAMA 191: 132-135, 1965.

32 - FREDETTE V. Numerical data concerning the sensivity of anaerobic bacteria to oxygen. J Bacteriol 94: 2012-2017, 1967.

33 - HIRN M. Hyperbaric oxygen in the treatment of gas gangrene and perineal necrotizing fasciitis. A clinical and experimental study. Eur J Surg: 1-36, 1993. Suppl 570.

34. - ERSAN et al. A Fournier gangrene. Arch Chir 380: 139-143, 1995.

35 - BROGAN TV et al. Group A streptococcal necrotizing fasciitis complicating primary varicella: a series of fourteen patients. Pediatr Infect Dis J 14: 588-594, 1995

36 - PELED M; RUBIN A \& LAUFER D. Cervical necrotizing fasciitis, Harefuah 126: 651-654, 1994.

37 - BROW et al. A multicenter review of major truncal necrotizing infections with or without hyperbaric oxygen therapy. Am J Surg 167: 485-489, 1994.

38 - TABRAH FL et al. Baromedicine today: rational uses of hypeerbaric oxygen therapy. Hawaii Med J 53: 112-115, 1994.

39 - HUDSON JW. Osteomyelitis of the jaws: a 50-year perspective. J Oral Maxillofac Surg 51: 1294-1301, 1993.

40 - KEMPER et al. Recovery from rhinocerebral mucormycosis in a ketoacidotic diabetic patient: a case report. J Laryngol Otol 107: 233-235, 1993.

41 - MUHVICH KH; MYERS RAM \& MARZELLA L. Effect of hyperbaric oxygenation, combined with antimicrobial agents and surgery, in a rat model of intraabdominal sepsis. $\mathbf{J}$ Infect Dis 157: 1058-1062, 1988.

42 - MORGAN RA et al. Oxygen free radical activity during live E. coli septic shock in the dog. Circ Shock 25: 319-323, 1988.

43 - BAST A; HAENEN RMM \& DOELMAN CJA. Oxidants and antioxidants: State of art. Am J Med 91(S3C): 1-13, 1991.

44 - OURY TD et al. Extracellular superoxide dismutase, nitric oxide and central nervous system O2 toxicity. Proc Natl Acad Sci 89: 9715-9719, 1992.

45 - MANTOVANI M et al. Efeitos da oxigenoterapia hiperbárica na peritonite fecal experimental. Rev Col Bras Cir 15: 84-86, 1989.

46 - IAZZETTI PE. Efeitos da hiperoxigenação hiperbárica na sepse por PLC em ratos: Aspectos microbiológicos, hematológicos e imunológicos. Tese de Doutorado, Faculdade de Ciências Médicas da UNICAMP, Campinas, 1996.

Recebido para publicação em 04/03/98

Aprovado para publicação em 13/05/98 